\title{
Tracing tectonic recycling, mantle heterogeneity, and melt transport processes with metal stable isotopes
}

\author{
H.M. Williams ${ }^{1}$, S. MATTHEWS ${ }^{1,2}$, C. SODERMAN ${ }^{1}, \mathrm{H}$. \\ FREYMUTH $^{1}$, M. SCHANNOR ${ }^{1}$ \\ ${ }^{1}$ The University of Cambridge, UK; hmw20@cam.ac.uk \\ ${ }^{2}$ Johns Hopkins University, USA; smatth36@jhu.edu
}

Previous studies have demonstrated that the mantle source regions sampled by ocean island basalts (OIB) are heterogenous at a range of lengthscales. This heterogeneity has been attributed to variations in mantle lithology and source region enrichment, created through the tectonic recycling of surface and near-surface material, prior melt extraction and source depletion in the upper mantle as well as the presence of primordial undegassed material, presumably located in the lower mantle. It is expected that variations in source lithology (including that created through the recycling of surface components) will directly track source history and in turn source lithology will exert a control on melt chemistry, reactions and transport processes. However, distinguishing between variations in mantle lithology and chemical enrichment as well as melting and transport processes is challenging. Metal stable isotopes may provide a solution to this problem. Some isotope systems, such as $\mathrm{Fe}$, respond to variations in mantle partial melting and melt transport processes and also show mineralspecific partitioning effects. Others, such as $\mathrm{Tl}$ and Mo, appear to principally record near-surface processes and the recycling of these components into the mantle while other metal stable isotope systems such as $\mathrm{Cu}$ document the interplay between both nearsurface and mantle processes. We will review the different mechanisms that have been proposed to drive stable isotope fractionation during these processes and discuss these in the light of literature and new data for magmas spanning a range of ages and tectonic settings. Our new data reveal a striking degree of short-wavelength stable isotope heterogeneity in both arcs and mantle plumes. This isotopic heterogeneity does not appear to be directly coupled to the subduction and recycling of surface components, or to the presence of distinct mantle end-members or to melting lithologies in a straightforward manner. Instead, it rather reflects the complex interplay of source composition and lithological control on partial melting and melt transport processes. 